\title{
Valoración del aspecto social en la evaluación del uso de la tierra
}

Propuesta metodológica

\section{Sandra Patricia Martínez B.* Zaida Liz Patiño Gómez* Olga Lucía Sánchez P.*1}

Resumen. El presente artículo es una propuesta metodológica para la valoración de los aspectos sociales dentro de la Evaluación del Uso de la Tierra. Se tomaron como referencia las características de las Unidades de Tierra Jaraquiel y Nariño, localizadas en el Valle del río Sinú y establecidas como tales en Estudio Básico para un Plan de Ocupación del Espacio ${ }^{2}$, rea lizado por el IGAC en el año 1987. La presente metodología es una pro puesta preliminar, que deberá ser enriquecida y ajustada en la medida en que se aplique a casos reales o se consideren otras perspectivas no tenidas en cuenta aquí. Palabras clave: evaluación del uso de la tierra, valoración de aspectos sociales en la evaluación del uso de la tierra.

*1 Sociólogas de la Universidad Nacional de Colombia. Candidatas al título de Magíster en Geografia, énfasis en Ordenamiento Territorial, Estudios de Posgrado en Geografía, Convenio UPTC-IGAC.

2 IGAC, Estudio Básico para un Plan de Ocupación del Espacio. Estudio de Uso de la Tierra y Cobertura, Alternativa de Ocupación del Medio Físico. CVS. Diciembre 1987. 


\section{Introducción}

Según el Servicio de Recursos, Manejo y Conservación de Suelos de la FAO, la Evaluación de Tierras es «la valoración de la explotación de la tierra cuando se utiliza con propósitos específicos. En este sentido ofrece una base racional para tomar decisiones relativas al uso de la tierra, basadas en el análisis de las relaciones entre la utilización de la tierra y la tierra misma» (FAO, 1985). No obstante, la utilización de la tierra depende a su vez no solamente de condiciones físicas, sino también de las relaciones sociales que allí se presenten.

En general, las metodologías aplicadas para la evaluación del uso de la tierra han hecho abstracción del componente social. Es el caso de metodologías como las de la FAO que han limitado el análisis de lo social a variables de tipo económico, sin dar cuenta de toda su complejidad. De tal modo que, su aplicación desde el punto de vista de políticas como el Ordenamiento Territorial, sigue siendo insuficiente en la medida en que no atiende los aspectos relacionados con el desarrollo social y el bienestar general, prioritarios dentro de este tipo de políticas.

En este sentido, se hace necesario adoptar metodologías más integrales que contribuyan a la toma de decisiones encaminadas a generar un verdadero mejoramiento de las condiciones de vida de la población, a partir de la integración de los componentes biofísicos, económicos $\mathrm{y}$ sociales.
Las experiencias mostradas hasta el presente pueden haber arrojado buenos resultados en términos físicos, pero muchas veces no han sido socialmente aceptadas, o han sido útiles tan solo en términos de crecimiento económico, generando o acentuando los desequilibrios sociales que hacen parte de nuestra realidad nacional.

La dimensión social resulta especialmente compleja en términos de la evaluación de tierras, dada la intrincada red de relaciones que la constituyen, así como la diversidad espacio temporal que la condiciona, es decir, que no se trata de un objeto estático sino dinámico, susceptible de múltiples variaciones de acuerdo a las especificidades de un lugar o momento histórico determinado.

Teniendo en cuenta lo anterior, la tarea de estandarizar parámetros para ser aplicables a cualquier lugar o momento, es sumamente difícil, pues en nuestro país cohabitan diferentes culturas, algunas de las cuales reproducen una racionalidad no necesariamente ligada al lucro y la obtención de excedentes económicos y para las cuales se exige la consideración de otros aspectos y/o otros parámetros de medición.

El esquema metodológico aplicado usualmente para la evaluación de uso de la tierra, por limitarse a la consideración de variables físicas y bióticas tiende a ser rígido y esquemático, lo cual limita la representación del componente social. La aproximación a la viabilidad social y la opción final de un determinado tipo de uso de la tierra, requiere un amplio trabajo de

178 Sandra Martínez B. - Zaida Patiño G. - Olga Sánchez P. 
campo, pues la información necesaria para hacer este tipo de valoración, debe apoyarse principalmente en fuentes primarias, recolectadas mediante diferentes técnicas tales como: entrevistas, encuestas, etnografía, observación participativa y no participativa, talleres, entre otros. Ante todo se debe saber cuál es la percepción y aceptación de la población en torno al cambio de sus actividades productivas, lo cual implica un trabajo de acercamiento y de concertación desde lo local. Consideramos que los procesos participativos se establecen como primera condición para realmente generar cambios y resultados significativos en la planificación del uso de la tierra.

Por último, es necesario precisar que la metodología aquí presentada constituye una primera aproximación que puede ser ajustada y enriquecida en la medida en que se aplique a situaciones concretas. Para efecto de la utilización de esta metodología se construyeron modelos hipotéticos de carácter social, referidos a las unidades de tierra Jaraquiel y Nariño, localizadas en el valle del río Sinú.

A continuación se expone la metodología seguida, así como los conceptos que guiaron el análisis.

\section{Metodología}

Aquí se describe el proceso que se siguió para la definición de las cualidades a tener en cuenta, su descripción y operacionalización, con el fin de establecer la oferta social para cada unidad de tierra. Posteriormente se definieron los tipos de utilización, de acuerdo a las condiciones físicas generales para, de esta manera, determinar los requerimientos por tipo de utilización de tierras.

El siguiente paso fue la confrontación de las tablas de oferta y demanda, con la cual se obtuvo una tabla final de aptitud actual por UT y otra de aptitud potencial por UT.

\subsection{Cualidades}

El criterio para la definición de las cualidades fue su pertinencia en el proceso de la valoración social aplicada a la evaluación de tierras. En primera instancia, se llevó a cabo una lluvia de ideas sobre las posibles cualidades a tener en cuenta, las cuales fueron decantadas, obteniéndose así, tan sólo las más significativas para dicha valoración. Algunas de estas cualidades se definieron a partir de otras que las caracterizaban. De esta manera se obtuvo:

a. Oferta de mano de obra.

b. Forma de Tenencia

- Tamaño predial

c. Nivel tecnológico

- Uso de tecnologías

- Uso de técnicas

d. Nivel de receptividad a los usos agropecuarios propuestos: 
- Ocupación por ramas de actividad

- Nivel de escolaridad

- Nivel de capacitación

Para el análisis de la cualidad Nivel de Receptividad, se tuvo en cuenta la variable Racionalidad Económica, que por su complejidad no es fácil de medir. Esta se divide en dos tipos:

- Racionalidad Económica cuya finalidad es la obtención de ganancia.

- Racionalidad Económica cuya finalidad no es la obtención de ganancia.

e. Capacidad de inversión:

- Rentabilidad de la actividad actual

- Uso del crédito

f. Mercadeo y comercialización:

- Costos de transporte

- Presencia de intermediarios

- Centros de acopio

- Distancia a centros de consumo

- Vías

g. Funcionalidad Espacial:

- Metrópolis

- Centros subregionales

- Centros de relevo

- Centros locales de primer orden

- Centros locales de segundo orden

- Centros veredales.

h. Servicios públicos: i. Orden Público:

- Delincuencia común

- Presencia de grupos armados

- Grado de influencia o control de los grupos armados

- Presencia de narcotráfico

- Posibilidad de negociación

j. Estructura de poder:

Con relación a esta variable, en la tabla correspondiente se observa que dicha estructura es clasificada según la tipología weberiana sobre la dominación (Weber, 1987), que incluye las siguientes categorías:

- Dominación Legal con Administración Burocrática

- Dominación Tradicional

- Dominación Carismática

k. Organización y Participación social: caracterizada por

- Espacios de participación

- Nivel de organización

- Grado de participación

- Influencia de la comunidad en la toma de decisiones.

Para la elaboración de las tablas de cada cualidad, se llevó a cabo la gradualización en Alto, Medio y Bajo, tratando de estandarizar y hacer posible que todo caso que se presente pueda ser clasificado dentro de ella.

- Agua

- Energía

180 Sandra Martínez B. - Zaida Patiño G. - Olga Sánchez P. 


\subsection{Definición y tablas de cualidades}

\subsubsection{Oferta de mano de obra}

Para medir la mano de obra disponible en la Unidad de Tierra, se toma como indicador la Población Económicamente Activa-PEA-, entendida como "el conjunto de personas en edad de trabajar que, durante el periodo de referencia, ejercieron o buscaron ejercer una ocupación remunerada en la producción de bienes y servicios; $y$ de aquellas personas que, en su condición de "ayudantes familiares", trabajaron sin remuneración". (DANE, 1993). Ello permite dar una idea de las potencialidades y limitantes respecto a las necesidades de mano de obra de determinado Tipo de Utilización de Tierra.

Las fuentes primarias para determinar la PEA en una Unidad de Tierra, no son las más adecuadas, ya que se requeriría de un censo poblacional, lo que en términos operativos es engorroso. Por tanto, y dado que el área de la Unidad de Tierra y las divisiones político-administrativas no coinciden, se recomienda utilizar información secundaria a partir de la cual, se puedan hacer inferencias acerca de la población por Unidad de Tierra. (Ver tabla No. 1).

Tabla No. 1

Tabla de oferta de mano de obra

\begin{tabular}{|l|c|}
\hline GRADO & POBLACIONECONOMICAMENTEACTIVA \\
\hline ALTO & El $50 \%$ o más de la población es económicamente activa \\
\hline MEDIO & Del 21 al $49 \%$ de la población es económicamente activa \\
\hline BAJO & Menos del $20 \%$ de la población es económicamente activa. \\
\hline
\end{tabular}

\subsubsection{Forma de tenencia de la tierra}

Dentro de esta categoría, se tuvieron en cuenta las formas de tenencia en propiedad, arrendamiento, aparcería y colonato, por ser las más comunes. Estas formas de tenencia, pueden definirse como:

\section{a. Propiedad privada o individual}

Significa que el propietario de la misma tiene, tanto el derecho de determinar el uso y gestión de sus tierras, como el derecho de pasar a terceros la propiedad mediante herencia, arrendamiento o venta.

\section{b. Arrendamiento}

Es un sistema de explotación de la tierra que consiste en la firma de un contrato por el que el campesino explota una tierra ajena, mediante el pago de una renta. Se trata pues, del uso de un espacio, mediante el pago de una cantidad estipulada. 
En ocasiones se combina el sistema de propiedad privada y de arrendamiento, así los grandes propietarios explotan parte de sus tierras y arriendan el resto. También existen medianos propietarios que cultivan sus propias tierras y las arrendadas a propietarios que generalmente no residen en el núcleo rural.

\section{c. Aparcería}

Es un sistema de contrato agrario por medio del cual el propietario de la tierra le cede una parte al campesino para su explotación, a cambio el propietario, recibe parte de la producción que se haya estipulado en concepto de renta. Por su parte el aparcero se compromete a cultivar la tierra de la forma convenida. La forma de aparcería más usual es aquella en que el propietario de la tierra ofrece el capital necesario fijo para la gestión de la explotación y los inmuebles, y el aparcero pone el trabajo. El propietario recibe una proporción, fijada con anterioridad, de la producción total.

\section{d. Colonato}

Comprende las tierras explotadas por un productor que carece de título de propiedad y puede usarlas sin pagar renta, no obstante, no puede retener el usufructo total. Las tierras ocupadas por estos productores pueden ser de propiedad pública o privada, y la ocupación tiene lugar sin el consentimiento del propietario, aun cuando a veces lo tolere, sobre todo en el caso de terrenos de dominio público. Este tipo de productor es llamado colono. (Ver tabla No. 2).

Tabla No. 2

Tabla de formas de tenencia de la tierra

\begin{tabular}{|l|l|}
\hline GRADO & \multicolumn{1}{c|}{ FORMASDE TENENCIA } \\
\hline ALTO & $\begin{array}{l}\text { El } 60 \% \text { o más de los predios son explotados por sus propietarios y el } 40 \% \\
\text { restante puede formarse por la combinación de arrendatarios y aparceros/ } \\
\text { colonos con predominio de los primeros. }\end{array}$ \\
\hline MEDIO & $\begin{array}{l}\text { (a) El } 60 \% \text { o más de los predios son explotados por arrendatarios y en el } \\
40 \% \text { restante predominan los propietarios. } \\
\text { (b) La mitad son propietarios y la otra mitad son aparceros/colonos o } \\
\text { arrendatarios. }\end{array}$ \\
\hline BAJO & $\begin{array}{l}\text { a) El } 60 \% \text { o más de los predios son explotados por aparceros/colonos. } \\
\text { b) El resultado de la suma de los predios explotados por arrendatarios y los } \\
\text { explotados por aparceros/colonos, es mayor del } 60 \% .\end{array}$ \\
\hline
\end{tabular}

182 Sandra Martínez B. - Zaida Patiño G. - Olga Sánchez P. 


\subsubsection{Tamaños prediales}

Teniendo en cuenta que la calificación del tamaño predial como gran, mediana y pequeña propiedad, depende de las condiciones tanto físicas como sociales de una región determinada, se tomaron como referencia, los tamaños de las explotaciones referidos a la Región Caribe, donde al igual que en zonas como los Llanos Orientales, predomina la gran propiedad.

Para esta región, se consideró entonces que las explotaciones entre 0 y 20 has. corresponden a la pequeña explotación (minifundio); entre 20 y 500 has a la mediana explotación; y las mayores de 500 has a la "gran explotación". Sin embargo, para tener una mejor idea de la forma de distribución de las explotaciones, en los tamaños intermedios, la clase de la mediana explotación, se subdividió así: de 20 a 50 has, de 50 a 200 has y de 200 a 500 has (IGAC, 1978).

Además de la superficie del predio, existen otros criterios que se contemplan para calificar el tamaño de la explotación, tales como la capacidad del productor de explotar su predio con o sin mano de obra contratada. (Ver tabla No. 3).

Tabla No. 3

Tabla de tamaños prediales

\begin{tabular}{|l|l|}
\hline GRADO & \multicolumn{1}{|c|}{ TAMAÑOS PREDIALES } \\
\hline ALTO & $\begin{array}{l}\text { Zona donde la superficie está concentrada en pocas manos con predios } \\
\text { superiores a 500 has }\end{array}$ \\
\hline MEDIO & $\begin{array}{l}\text { MEDIO ALTO: zona donde la mayor parte de la superficie son predios de } \\
\text { 350 a 500 has }\end{array}$ \\
\hline & $\begin{array}{l}\text { MEDIO MEDIO: zona donde la mayor parte de la superficie son predios de } \\
150 \text { a 350 has }\end{array}$ \\
\hline BAJO & $\begin{array}{l}\text { MEDIO BAJO: zona donde la mayor parte de la superficie son predios de 20 a } \\
150 \text { has }\end{array}$ \\
\hline $\begin{array}{l}\text { BAJO: Zona donde la mayor parte de la superficie está distribuida en } \\
\text { propiedades entre 20 y 3 has } \\
\text { MUY BAJO: Zona donde la mayor parte de la superficie son microfundio, es }\end{array}$ \\
\hline
\end{tabular}




\subsubsection{Pequeña propiedad}

Es aquella que absorbe totalmente la capacidad de trabajo del cultivador y su familia, sin ayuda de trabajo extraño. Dentro de esta se encuentra el Microfundio.

\subsection{Microfundio}

Dentro del concepto de pequeña propiedad cabe el de microfundio, que es el caso de parcelas reducidas que no alcanzan a satisfacer las necesidades de la familia, por lo cual el cultivador debe buscarse labores complementarias, generalmente el trabajo asalariado; puede considerarse que todo fundo inferior a tres hectáreas cabe dentro de esta clasificación.

\subsubsection{Mediana propiedad}

Es aquella que absorbe la capacidad de trabajo del cultivador y su familia y aún de algunos extraños a la misma.

\subsubsection{Gran propiedad}

Puede definirse como aquella en que el propietario o empresario no trabaja manualmente, limitándose a dirigir la explotación en la cual esté o no ausente, de manera que ella se adelanta de modo exclusivo con trabajo extraño. Se distingue en esta categoría la hacienda y el latifundio.

\subsection{Hacienda}

Se caracteriza por la técnica y la gran productividad por unidad de trabajo y de superficie, con cuantiosas inversiones de capital, bien sea que se dedique a los cultivos intensivos o a la ganadería del mismo tipo prevaleciendo el trabajo asalariado.

\subsection{Latifundio}

Es una extensa propiedad que no ha sido dedicada a usos productivos, ya sea por hallarse en áreas remotas o por presentar prácticas agrícolas de tipo extensivo en regiones donde ese tipo no se justifica económicamente. Se presenta una explotación rudimentaria, sin la aplicación de técnicas nuevas, de tipo extensivo. Hay un predominio absoluto de la mano de obra, pues la mecanización y el uso de capital son nulos.

Existe un contraste entre hacienda y latifundio. En el último predomina el factor naturaleza, esto es la tierra y los cultivos de extensión, mientras que en aquella, el factor sobresaliente es el capital, uso de equipo y de técnicas que facilitan la producción intensiva.

\subsubsection{Nivel tecnológico de la producción}

Los dos aspectos tenidos en cuenta para valorar esta cualidad son: tecnología y técnicas utilizadas, entendiéndose por éstas:

\section{a. Tecnología}

Se refiere al grado de mecanización alcanzado en una determinada explotación, e incluye: maquinaria agrícola, con máquinas tales como tractor, abonadora y

184 Sandra Martínez B. - Zaida Patiño G. - Olga Sánchez P. 
sembradora e implementos como los abrevaderos, saladeros y cercas eléctricas.

\section{b. Técnicas}

Hacen alusión a los procedimientos y métodos empleados por el productor, los cuales pueden medirse, desde aquellas más tradicionales hasta las más avanzadas. Entre las técnicas se cuentan: con- trol de malezas, resiembras, rotación de potreros, mezcla de leguminosas con gramíneas, bancos de proteínas, bloques multinutricionales, sanidad animal, mejoramiento genético e inseminación artificial.

En la tabla número 4 se puede apreciar la categorización de los anteriores conceptos.

Tabla No. 4

Tabla de nivel tecnológico

\begin{tabular}{|c|c|c|}
\hline GRADO & TECNOLOGÍA & TECNICAS \\
\hline ALTO & $\begin{array}{l}\text { (a) El } 60 \% \text { o más de los productores } \\
\text { utilizan tecnologías avanzadas. } \\
\text { El } 40 \% \text { puede formarse por los que } \\
\text { utilizan baja tecnología y/o los que } \\
\text { combinan alta y baja tecnología } \\
\text { a la vez }\end{array}$ & $\begin{array}{l}\text { a) La mitad o más de los productores } \\
\text { utilizan técnicas adecuadas }\end{array}$ \\
\hline \multirow[t]{2}{*}{ MEDIO } & $\begin{array}{l}\text { a) El resultado de la suma de los } \\
\text { productores que utilizan tecnologías } \\
\text { avanzadas y los que combinan entre } \\
\text { avanzadas y simples a la vez, } \\
\text { es la mitad o más. }\end{array}$ & $\begin{array}{l}\text { a) El resultado de la suma de los } \\
\text { propietarios que utilizan técnicas } \\
\text { adecuadas y los que combinan } \\
\text { adecuadas e inadecuadas a la vez, } \\
\text { es la mitad o más. }\end{array}$ \\
\hline & $\begin{array}{l}\text { (b) La mitad de los productores } \\
\text { utilizan tecnologías avanzadas y la } \\
\text { otra mitad herramientas simples }\end{array}$ & $\begin{array}{l}\text { b) La mitad de los productores utilizan } \\
\text { técnicas adecuadas y la otra } \\
\text { mitad inadecuadas. }\end{array}$ \\
\hline \multirow[t]{2}{*}{ BAJO } & $\begin{array}{l}\text { a) El } 60 \% \text { o más de los productores } \\
\text { utilizan herramientas simples. }\end{array}$ & $\begin{array}{l}\text { c) La mitad o más de los productores } \\
\text { utilizan técnicas inadecuadas. }\end{array}$ \\
\hline & $\begin{array}{l}\text { b) La mitad de los productores utilizan } \\
\text { herramientas simples y la otra mitad } \\
\text { combinan las simples con las } \\
\text { avanzadas. }\end{array}$ & $\begin{array}{l}\text { d) La mitad de los productores utilizan } \\
\text { técnicas inadecuadas y la otra } \\
\text { mitad combina las adecuadas con } \\
\text { las inadecuadas. }\end{array}$ \\
\hline
\end{tabular}




\subsubsection{Nivel de receptividad}

Se consideró adecuado emplear como indicadores de esta cualidad:

\section{a. Ocupación por ramas de actividad de la población}

Se considera muy factible el cambio a un Tipo de Utilización de la Tierra agropecuario determinado, si la vocación de la población ha sido ésta, teniendo en cuenta el factor tradición y/o costumbre, así como la oferta natural que brinda el lugar. De igual forma, es necesario considerar los patrones y valores culturales, asociados a una determinada actividad productiva ya que éstos influyen sobre la valoración o el arraigo a una actividad específica y por tanto, en la resistencia o receptividad al cambio. Sin embargo, aquí se trabajó de manera general, es decir tomando como referencia la actividad agropecuaria en general sin considerar las diferencias de sus distintas actividades.

\section{b. Nivel de escolaridad}

Como indicador de receptividad es un factor de suma importancia teniendo en cuenta el efecto de la escuela o la educación formal en la modificación, ruptura o afianzamiento de determinados esquemas culturales. De tal modo, se parte de considerar el nivel de escolaridad como un elemento facilitador del cambio.

\section{c. Nivel de capacitación}

$\mathrm{Al}$ igual que el anterior, se hace referencia al acumulado de conocimientos específicos que en determinado momento califican un nivel de aptitud social para la adopción de cambios o de determinadas formas de producción.

En la tabla número 5 se presenta la categorización de los anteriores conceptos.

\subsubsection{Capacidad de inversión del productor}

Esta cualidad se tomó en cuenta partiendo de la idea que la implementación de cualquier tipo de explotación, requiere un mínimo de capital para invertir, sobre todo, los evaluados aquí como: arroz y pastos. De esta forma, se tomaron los siguientes parámetros:

\section{a. Rentabilidad de la actividad actual}

Permite conocer o dar una idea sobre la capacidad del productor en términos económicos para adoptar un determinado tipo de cultivo.

\section{b. Acceso al crédito}

Influye directamente en la posibilidad de que el productor en un momento dado, pueda disponer de un capital considerable para invertir.

186 Sandra Martínez B. - Zaida Patiño G. - Olga Sánchez P. 
Tabla No. 5

Tabla de nivel de receptividad

\begin{tabular}{|c|c|c|c|c|c|}
\hline GRADO & $\begin{array}{c}\text { OCUPACION POR } \\
\text { RAMAS DE LA } \\
\text { ACTIVIDAD }\end{array}$ & & $\begin{array}{c}\text { NIVEL DE } \\
\text { ESCOLARIDAD }\end{array}$ & $\begin{array}{c}\text { NIVEL DE } \\
\text { CAPACITACION }\end{array}$ & $\begin{array}{l}\text { RACIONALIDAD } \\
\text { ECONOMICA* }\end{array}$ \\
\hline ALTO & $\begin{array}{l}\text { a) Zona donde más del } \\
50 \% \text { de la población } \\
\text { económicamente activa, } \\
\text { se dedica a actividades } \\
\text { agropecuarias }\end{array}$ & & $\begin{array}{l}\text { Más del } 50 \% \text { de los } \\
\text { productores han } \\
\text { terminado la secundaria } \\
\text { o han cursado estudios } \\
\text { técnicos o superiores. }\end{array}$ & $\begin{array}{l}\text { a) Más del } 50 \% \text { de los productores } \\
\text { agropecuarios asisten } \\
\text { frecuentemente a talleres } \\
\text { ofrecidos por alguna organización } \\
\text { o institución que trabaje con el } \\
\text { sector agropecuario. } \\
\text { c) E1 } 50 \% \text { asiste frecuentemente y el } \\
\text { otro } 50 \% \text { asiste ocasionalmente }\end{array}$ & $\begin{array}{l}\text { a) Tipo A: UT donde la } \\
\text { mayor parte de los } \\
\text { productores cuentan con } \\
\text { un tipo de racionalidad } \\
\text { económica cuyo fin es la } \\
\text { obtención de excedentes. } \\
\text { Tipo B:UT donde la mayor } \\
\text { parte de los productores } \\
\text { cuentan con un tipo de } \\
\text { racionalidad cuyo fin no es } \\
\text { la obtención de excedente } \\
\text { sino una economía de } \\
\text { subsistencia }\end{array}$ \\
\hline MEDIO & $\begin{array}{l}\text { a) Zona donde la población } \\
\text { económicamente activa } \\
\text { que trabaja en actividades } \\
\text { agropecuarias representa } \\
\text { entre el } 20 \text { y el } 50 \%\end{array}$ & a) & $\begin{array}{l}\text { Más del } 50 \% \text { de los } \\
\text { productores agrope- } \\
\text { cuarios han cursado } \\
\text { algunos grados } \\
\text { de secundaria }\end{array}$ & $\begin{array}{l}\text { a) El } 50 \% \text { de lo P. A asiste } \\
\text { ocasionalmente y más del } 25 \% \text { de la } \\
\text { otra mitad asiste frecuentemente. } \\
\text { (b) El } 50 \% \text { asiste frecuentemente } \\
\text { y el otro } 50 \% \text { bien puede repartirse } \\
\text { entre los que asisten ocasionalmente } \\
\text { y los que nunca o solo han } \\
\text { asistido algunas veces. }\end{array}$ & \\
\hline BAJO & $\begin{array}{l}\text { a) Zona donde la población } \\
\text { económicamente activa que } \\
\text { se ocupa en actividades } \\
\text { agropecuarias representa } \\
\text { menos del } 20 \% \\
\end{array}$ & b) & $\begin{array}{l}\text { Más del } 50 \% \text { de los } \\
\text { productores agropecuarios } \\
\text { sólo ha cursado la primaria } \\
\text { completa o incompleta } \\
\text { o es analfabeta. }\end{array}$ & $\begin{array}{l}\text { a) El } 50 \% \text { o más de los productores } \\
\text { nunca han asistido } \\
\text { b) La suma de los que asisten } \\
\text { ocasionalmente y los que nunca } \\
\text { asisten es más del } 50 \% \text {. }\end{array}$ & \\
\hline
\end{tabular}


En la tabla No. 6 se presenta la categorización de las anteriores definiciones.

\subsubsection{Mercadeo o comercialización}

Para la definición de esta cualidad, se tuvieron en cuenta los siguientes aspectos:

\section{a. Costos de transporte}

Aspecto considerado en términos de su afectación sobre la rentabilidad de la explotación.

\section{b. Presencia de intermediarios}

Mide hasta qué punto la comercialización es directa o está mediada por agentes distintos al productor.

Tabla No 6

\section{Tabla de capacidad de inversión}

\begin{tabular}{|c|c|c|}
\hline GRADO & RENTABILIDAD & CREDITO \\
\hline ALTO & $\begin{array}{l}\text { a) Más de la mitad de los predios } \\
\text { genera una rentabilidad del } 100 \% \\
\text { o más } \\
\text { a) La mitad o más de los predios } \\
\text { genera una rentabilidad entre } \\
\text { el } 50 \text { y el } 99.9 \% \text {. }\end{array}$ & $\begin{array}{l}\text { a) Más de la mitad de los propietarios } \\
\text { ha tenido acceso al crédito en tres } \\
\text { o más oportunidades y ha podido } \\
\text { subvencionarlo } \\
\text { a) La mitad o más de los productores } \\
\text { ha tenido acceso al crédito entre } \\
\text { una y tres oportunidades y lo pudo } \\
\text { subvencionar }\end{array}$ \\
\hline \multirow[t]{2}{*}{ MEDIO } & $\begin{array}{l}\text { b) La mitad de los predios genera } \\
\text { ganancia del } 100 \% \text { o más y la otra } \\
\text { mitad de genera ganancias } \\
\text { inferiores al } 50 \% \text { o negativas }\end{array}$ & $\begin{array}{l}\text { b) Los productores que han tenido } \\
\text { acceso al crédito entre una y tres } \\
\text { oportunidades y los que han tenido } \\
\text { crédito tres o más oportunidades } \\
\text { suman la mitad o más de los predios. }\end{array}$ \\
\hline & $\begin{array}{l}\text { c) La suma de los predios que generan } \\
\text { rentabilidad del } 100 \% \text { o más y los } \\
\text { que generan rentabilidad entre el } \\
50 \text { y el } 99.9 \% \text {, da la mitad o más } \\
\text { de los predios. }\end{array}$ & $\begin{array}{l}\text { c) La mitad de los productores ha } \\
\text { tenido acceso al crédito en más de } \\
\text { tres oportuniddes y la otra mitad no } \\
\text { ha tenido acceso al crédito o ha } \\
\text { tenido pero no ha podido subven- } \\
\text { cionarlo. }\end{array}$ \\
\hline BAJO & $\begin{array}{l}\text { a) Más de la mitad de los predios } \\
\text { genera una rentabilidad negativa } \\
\text { o inferior al } 50 \% \text {. }\end{array}$ & $\begin{array}{l}\text { a) Más de la mitad de los productores } \\
\text { ha tenido acceso al crédito y no ha } \\
\text { logrado pagar, o nunca ha tenido } \\
\text { acceso al crédito, por razones } \\
\text { económicas. }\end{array}$ \\
\hline
\end{tabular}

188 Sandra Martínez B. - Zaida Patiño G. - Olga Sánchez P. 


\section{c. Centros de acopio}

Busca determinar si la infraestructura existente satisface las necesidades de almacenamiento del producto.

\section{d. Distancia a centros de consumo}

Como su nombre lo indica, mide la accesibilidad a los sitios donde será consumido el producto.

\section{e. Vías}

Su calidad y cobertura influye en forma determinante en la comercialización de los productos.

En la tabla número 7 se aprecian los factores tenidos en cuenta para la valoración de este aspecto.

\subsubsection{Funcionalidad espacial}

Se considera pertinente tener en cuenta este componente para establecer la relación, en términos de funcionalidad espacial, entre la unidad de tierra y los diferentes centros urbanos. Para ello se involucra la clasificación urbano regional de Colombia, (IGAC, 1986) complementada con la propuesta presentada para el análisis de este aspecto en la Guía metodológica para el Ordenamiento Territorial Municipal (IGAC, 1997), las cuales clasifican los centros urbanos como:

\section{a. Metrópolis}

\section{b. Centros subregionales}

c. Centros de relevo

\section{d. Centros locales de primer orden}

e. Centros locales de segundo orden

\section{f. Centros veredales.}

Para efectos del presente trabajo se toman en cuenta sólo los centros subregionales, los centros locales o cabeceras municipales y los centros veredales, por ser estos los que mayor diferenciación muestran.

Este aspecto da idea de las potencialidades o limitantes que tiene el establecimiento de un determinado producto, en términos de su conexión con un núcleo o polo urbano tanto para la comercialización, como de los servicios que este le pueda proveer. Se hace la gradualización en Alto, Medio y Bajo, tomando en cuenta que lo más óptimo es el vínculo a un sistema integral y equilibrado es decir, en un complejo funcional asociado a las tres categorías analizadas.

En la tabla número 8 se observa la clasificación de los anteriores aspectos. 


\begin{tabular}{|c|c|c|c|c|c|}
\hline \multicolumn{6}{|c|}{$\begin{array}{c}\text { Tabla No. } 7 \\
\text { Tabla de mercadeo y comercialización }\end{array}$} \\
\hline GRADO & $\begin{array}{c}\text { COSTOS } \\
\text { DE TRANSPORTE }\end{array}$ & $\begin{array}{l}\text { PRESENCIA } \\
\text { INTERMEDIA }\end{array}$ & $\begin{array}{l}\text { CENTRO } \\
\text { DE ACOPIO }\end{array}$ & $\begin{array}{c}\text { DISTANCIA CENTROS } \\
\text { CONSUMO }\end{array}$ & VIAS \\
\hline A L T O & $\begin{array}{l}\text { a. Más de la mitad de los } \\
\text { productores paga costos } \\
\text { de transporte que no le im- } \\
\text { pide obtener ganancia óp- } \\
\text { tima. } \\
\text { b. La mitad de los produc- } \\
\text { tores paga costos de trans- } \\
\text { porte que le permiten ob- } \\
\text { tener ganancia óptima y la } \\
\text { otra mitad, paga costos de } \\
\text { transporte que le permiten } \\
\text { obtener ganancia significa- } \\
\text { tiva. }\end{array}$ & $\begin{array}{l}\text { a. Más de la mitad de los } \\
\text { productores comercializa } \\
\text { directamente sus produc- } \\
\text { tos. } \\
\text { b. La mitad de los produc- } \\
\text { tores comercializa directa- } \\
\text { mente sus productos y la } \\
\text { otra mitad, utiliza un in- } \\
\text { termediario. } \\
\text { c. La mitad de los produc- } \\
\text { tores comercializa sus } \\
\text { productos directamente y } \\
\text { en la otra mitad predomi- } \\
\text { nan aquellos que utilizan } \\
\text { un sólo intermediario. }\end{array}$ & $\begin{array}{l}\text { a. Más de la mitad de los } \\
\text { productores tiene acceso a } \\
\text { uno o más centros de aco- } \\
\text { pio adecuados a las nece- } \\
\text { sidades de almacenamien- } \\
\text { to del producto. } \\
\\
\text { b. La mitad de los propie- } \\
\text { tarios tiene acceso a uno o } \\
\text { más centros de acopio que } \\
\text { suplen las necesidades de } \\
\text { almacenamiento y la otra } \\
\text { mitad suplen medianamen- } \\
\text { te dichas necesidades. } \\
\text { c. La mitad de los produc- } \\
\text { tores tiene acceso a centros } \\
\text { de acopio suficientes y en } \\
\text { la otra mitad predominan } \\
\text { aquellos que suplen media- } \\
\text { namente estas necesidades. }\end{array}$ & $\begin{array}{l}\text { a. Más de la mitad de los } \\
\text { productores recorre un } \\
\text { trayecto de dos horas o } \\
\text { menos para llegar a los cen- } \\
\text { tros de consumo. } \\
\text { b. La mitad de los produc- } \\
\text { tores recorre un trayecto } \\
\text { inferior a dos horas y la } \\
\text { otra mitad recorre un tra- } \\
\text { yecto entre } 2 \text { y } 4 \text { horas } \\
\text { para llegar a los centros de } \\
\text { consumo. } \\
\text { c. La mitad de los produc- } \\
\text { tores recorre un trayecto } \\
\text { inferior a dos horas y en la } \\
\text { otra mitad predominan } \\
\text { aquellos que recorren en- } \\
\text { tre } 2 \text { y } 4 \text { horas. }\end{array}$ & $\begin{array}{l}\text { a. Más de la mitad de los } \\
\text { predios cuenta con un nú- } \\
\text { mero de vías suficiente y } \\
\text { en buen estado. } \\
\text { b. La mitad de los predios } \\
\text { cuenta con suficientes vías } \\
\text { y la otra mitad cuenta con } \\
\text { vías suficientes pero en re- } \\
\text { gular estado. } \\
\text { c. La mitad de los predios } \\
\text { cuenta con vías suficien- } \\
\text { tes y en la otra mitad pre- } \\
\text { dominan las vías en regu- } \\
\text { lar estado. }\end{array}$ \\
\hline
\end{tabular}




\begin{tabular}{|c|c|c|c|c|c|}
\hline MEDIO & $\begin{array}{l}\text { a. Los productores que } \\
\text { pagan costos de transpor- } \\
\text { te que no les impide obte- } \\
\text { ner ganancia óptima y los } \\
\text { que pagan costos de trans- } \\
\text { porte que les permiten } \\
\text { obtener ganancia significa- } \\
\text { tiva, suman la mitad o más } \\
\text { de los predios. } \\
\text { b. Los productores que pa- } \\
\text { gan costos de transporte } \\
\text { que les permiten obtener } \\
\text { ganancia óptima y los que } \\
\text { pagan costos de transpor- } \\
\text { te que no les permiten } \\
\text { obtener ganancia, o que les } \\
\text { genera pérdida, suman la } \\
\text { mitad o más de los predios. } \\
\text { c. La mitad o más de los } \\
\text { productores, paga costos de } \\
\text { transporte que no les } \\
\text { impide obtener ganancia } \\
\text { significativa. }\end{array}$ & $\begin{array}{l}\text { a. La mitad o más de los } \\
\text { productores comercializa } \\
\text { sus productos pasando } \\
\text { por un intermediario. } \\
\text { b. Los productores que } \\
\text { comercializan sus produc- } \\
\text { tos directamente y los } \\
\text { productores que utilizan } \\
\text { más de un intermediario } \\
\text { suman la mitad o más. } \\
\text { c. Los productores que } \\
\text { comercializan sus produc- } \\
\text { tos directamente y aque- } \\
\text { llos cuyos productos } \\
\text { pasan por las manos de } \\
\text { más de un intermediario, } \\
\text { suman la mitad o más de } \\
\text { los predios, siempre y } \\
\text { cuando en esta suma } \\
\text { predominen estos últimos. }\end{array}$ & $\begin{array}{l}\text { a. Más de la mitad de los } \\
\text { productores tienen acceso } \\
\text { a centros de acopio sufi- } \\
\text { cientes. } \\
\text { b. Los productores que } \\
\text { tienen acceso a centros de } \\
\text { acopio suficientes, y los } \\
\text { que no cuentan con } \\
\text { centros de acopio que } \\
\text { satisfagan estas necesida- } \\
\text { des, suman la mitad o más } \\
\text { de los predios. } \\
\text { c. Los productores que } \\
\text { tienen acceso a centros de } \\
\text { acopio suficientes y los } \\
\text { que cuentan con centros } \\
\text { de acopio que no suplen } \\
\text { estas necesidades, suman } \\
\text { la mitad o más de los } \\
\text { productores, siempre y } \\
\text { cuando en esta suma } \\
\text { predominen los últimos. }\end{array}$ & $\begin{array}{l}\text { a. Más de la mitad de los } \\
\text { productores recorre un } \\
\text { trayecto de } 2 \text { a } 4 \text { horas para } \\
\text { llegar a los centros de } \\
\text { consumo. } \\
\text { b. Los productores que } \\
\text { recorren } 2 \text { horas o menos } \\
\text { y los que recorren un } \\
\text { trayecto de } 4 \text { horas o más, } \\
\text { suman la mitad o más. } \\
\text { c. Los que recorren un } \\
\text { trayecto de } 2 \text { horas o } \\
\text { menos y los que recorren } \\
\text { un trayecto entre } 2 \text { y } 4 \\
\text { horas, para llegar a los } \\
\text { centros de consumo, suman } \\
\text { la mitad o más, siempre y } \\
\text { cuando en esta suma, } \\
\text { predominen estos últimos. }\end{array}$ & $\begin{array}{l}\text { a. La mitad o más de los } \\
\text { predios cuenta con vías } \\
\text { suficientes pero en regu- } \\
\text { lar estado. } \\
\text { b. Los predios que cuen- } \\
\text { tan con vías suficientes y } \\
\text { en buen estado y los que } \\
\text { cuentan con vías suficien- } \\
\text { tes pero en regular estado, } \\
\text { suman la mitad o más de } \\
\text { los predios. } \\
\text { c. Los predios que cuen- } \\
\text { tan con suficientes vías } \\
\text { pero en regular estado y } \\
\text { aquellos donde no hay vías } \\
\text { o estas son insuficientes } \\
\text { y en mal estado suman la } \\
\text { mitad o más de los } \\
\text { predios, siempre y cuan- } \\
\text { do en esta suma predomi- } \\
\text { nen estas últimas. }\end{array}$ \\
\hline BAJO & $\begin{array}{l}\text { a. Los predios que pagan } \\
\text { costos de transporte que les } \\
\text { impide obtener ganancia o } \\
\text { que les genera pérdida, } \\
\text { representan más de la } \\
\text { mitad de los predios. }\end{array}$ & $\begin{array}{l}\text { a. Más de la mitad de los } \\
\text { productores comercializa } \\
\text { sus productos, pasando } \\
\text { por más de un intermedia- } \\
\text { rio. }\end{array}$ & $\begin{array}{l}\text { a. Más de la mitad de los } \\
\text { productores no tiene } \\
\text { acceso a centros de acopio } \\
\text { que suplan las necesidades } \\
\text { de almacenamiento del } \\
\text { producto. }\end{array}$ & $\begin{array}{l}\text { a. Los productores que re- } \\
\text { corren un trayecto de más } \\
\text { de } 4 \text { horas para llegar a los } \\
\text { centros de consumo, re- } \\
\text { presentan más de la mitad } \\
\text { del total. }\end{array}$ & $\begin{array}{l}\text { a. Más de la mitad de los } \\
\text { predios no cuenta con } \\
\text { vías, o estas son insufi- } \\
\text { cientes y en mal estado, } \\
\text { representan más de la mi- } \\
\text { tad de los predios. }\end{array}$ \\
\hline
\end{tabular}


Tabla No 8

Tabla de funcionalidad espacial

\begin{tabular}{|c|c|}
\hline GRADO & FUNCIONALIDAD ESPACIAL \\
\hline ALTO & $\begin{array}{l}\text { a) Más de la mitad de los predios tiene una funcionalidad espacial alta, es decir, } \\
\text { son funcionales a centros subregionales, cabeceras municipales y veredas. } \\
\text { b) La mitad de los predios tiene una funcionalidad alta, la otra mitad, una media, } \\
\text { o sea que sólo están conectados a cabeceras municipales y veredas. } \\
\text { c) La mitad de los predios tiene una funcionalidad alta, en la otra mitad } \\
\text { predominan aquellos que poseen una funcionalidad media. }\end{array}$ \\
\hline MEDIO & $\begin{array}{l}\text { a) Más de la mitad de los predios tiene una funcionalidad media, es decir, están } \\
\text { conectados a cabeceras municipales y a veredas. } \\
\text { b) Los predios que tienen una funcionalidad media y aquellos que tienen una } \\
\text { alta, suman la mitad o más de los predios. } \\
\text { c) Los predios que tienen una funcionalidad media y los que tienen una } \\
\text { funcionalidad baja, suman la mitad o más de los predios, siempre y cuando en } \\
\text { la suma predominen estos últimos. }\end{array}$ \\
\hline BAJO & $\begin{array}{l}\text { a) Más de la mitad de los predios tiene una baja funcionalidad, o sea, que sólo } \\
\text { están conectados a sistemas veredales. }\end{array}$ \\
\hline
\end{tabular}

\subsubsection{Servicios públicos}

Esta cualidad incluye energía y acueducto, teniendo en cuenta que la mayoría de usos de la tierra que se pueden proponer, pueden requerir este tipo de servicios.

En la tabla número 9 se puede observar la clasificación de este aspecto.

\subsubsection{Orden público}

Se toma en cuenta esta característica, dada la importancia que tiene este factor para considerar la viabilidad en la implementación de determinados usos del suelo. Es inminente el papel que juegan los problemas de orden público en la dinámica económica y social de determinada área geográfica, implicando generalmente limitantes difíciles de manejar pero que reconocidas y analizadas, dan luz sobre las diferentes formas como se puede abordar la búsqueda de soluciones concertadas.

En la tabla número 10 se puede observar la categorización de los anteriores aspectos.

192 Sandra Martínez B. - Zaida Patiño G. - Olga Sánchez P. 
Tabla No. 9

Tabla de servicios públicos

\begin{tabular}{|c|c|c|}
\hline GRADO & SERVICIODE AGUA & ENERGIA \\
\hline ALTO & $\begin{array}{l}\text { a) Más de la mitad de los predios } \\
\text { cuenta con una adecuada } \\
\text { cobertura y calidad del servicio. } \\
\text { b) La mitad de los predios cuenta } \\
\text { con una adecuada calidad y } \\
\text { cobertura del servicio y la otra } \\
\text { mitad cuenta con una mediana } \\
\text { calidad y cobertura de agua. } \\
\text { c) La mitad de los predios cuenta } \\
\text { con una adecuada calidad y } \\
\text { cobertura del servicio y en la } \\
\text { otra mitad predominan los } \\
\text { predios que tienen una mediana } \\
\text { calidad y cobertura del servicio. }\end{array}$ & $\begin{array}{l}\text { a) Más de la mitad de los predios } \\
\text { cuenta con una adecuada cobertura } \\
\text { y calidad del servicio. } \\
\text { b) La mitad de los predios cuenta con } \\
\text { una adecuada calidad y cobertura del } \\
\text { servicio y la otra mitad cuenta con una } \\
\text { mediana calidad y cobertura de } \\
\text { energía. } \\
\text { c) La mitad de los predios cuenta con } \\
\text { una adecuada calidad y cobertura del } \\
\text { servicio y en la otra mitad predominan } \\
\text { los predios que tienen una mediana } \\
\text { calidad y cobertura del servicio. }\end{array}$ \\
\hline MEDIO & $\begin{array}{l}\text { a) La mitad o más de los predios } \\
\text { cuenta con una mediana calidad } \\
\text { y cobertura del servicio. } \\
\text { b) La mitad o más de los predios } \\
\text { está representada en aquellos que } \\
\text { poseen una calidad y cobertura } \\
\text { del servicio adecuada, y en aquellos } \\
\text { que tienen una mediana calidad y } \\
\text { cobertura de dicho servicio. } \\
\text { c) La mitad o más de los predios está } \\
\text { representada en aquellos que } \\
\text { cuentan con una mediana calidad } \\
\text { y cobertura del servicio, y aquellos } \\
\text { en los que no existe el servicio, } \\
\text { o es insuficiente, siempre y cuando } \\
\text { en esta mitad predominen los } \\
\text { últimos. }\end{array}$ & $\begin{array}{l}\text { a) La mitad o más de los predios cuenta } \\
\text { con una mediana calidad y cobertura } \\
\text { del servicio. } \\
\text { b) La mitad o más de los predios está } \\
\text { representada en aquellos que poseen } \\
\text { una calidad y cobertura del servicio } \\
\text { adecuada, y en aquellos que tienen } \\
\text { una mediana calidad y cobertura } \\
\text { de dicho servicio. } \\
\text { c) La mitad o más de los predios está } \\
\text { representada en aquellos que cuentan } \\
\text { con una mediana calidad y cobertura } \\
\text { del servicio, y aquellos en los que no } \\
\text { existe el servicio, o es insuficiente, } \\
\text { siempre y cuando en esta mitad } \\
\text { predominen los últimos. }\end{array}$ \\
\hline BAJO & $\begin{array}{l}\text { a) Más de la mitad de los predios no } \\
\text { cuenta con el servicio, o éste es } \\
\text { insuficiente. }\end{array}$ & $\begin{array}{l}\text { a) Más de la mitad de los predios no } \\
\text { cuenta con el servicio, o éste } \\
\text { es insuficiente. }\end{array}$ \\
\hline
\end{tabular}




\begin{tabular}{|c|c|c|c|c|c|}
\hline \multicolumn{6}{|c|}{$\begin{array}{l}\text { Tabla No. } 10 \\
\text { Tabla de orden público }\end{array}$} \\
\hline GRADO & $\begin{array}{l}\text { DELINCUENCIA } \\
\text { COMUN }\end{array}$ & $\begin{array}{l}\text { PRESENCIA } \\
\text { GRUPOS } \\
\text { ARMADOS }\end{array}$ & $\begin{array}{l}\text { GRADO DE } \\
\text { INFLUENCIA } \\
\text { GRUPOS } \\
\text { ARMADOS }\end{array}$ & NARCOTRAFICO & $\begin{array}{c}\text { POSIBILIDAD } \\
\text { DE NEGOCIACION }\end{array}$ \\
\hline ALTO & $\begin{array}{l}\text { Zona donde se presenta } \\
\text { baja frecuencia de delitos } \\
\text { como: secuestro, hurto, } \\
\text { homicidio, abigeato y } \\
\text { extorsión }\end{array}$ & $\begin{array}{l}\text { Zona donde no hay } \\
\text { presencia de grupos } \\
\text { armados }\end{array}$ & $\begin{array}{l}\text { Zona donde no existe } \\
\text { control social, político } \\
\text { y económico por parte } \\
\text { de alguno o todos los } \\
\text { grupos armados. }\end{array}$ & $\begin{array}{l}\text { Zona donde no hay } \\
\text { presencia del } \\
\text { narcotráfico. }\end{array}$ & $\begin{array}{l}\text { Zona donde existen } \\
\text { canales o espacios de } \\
\text { comunicación ya } \\
\text { establecidos. }\end{array}$ \\
\hline MEDIO & $\begin{array}{l}\text { Zona donde se presentan } \\
\text { con moderada frecuencia } \\
\text { los delitos antes } \\
\text { mencionados. }\end{array}$ & $\begin{array}{l}\text { Zona donde hay } \\
\text { presencia de sólo uno } \\
\text { de los grupos armados. }\end{array}$ & $\begin{array}{l}\text { Zona donde el control } \\
\text { ejercido por los grupos } \\
\text { armados es moderado. }\end{array}$ & $\begin{array}{l}\text { Zona donde hay } \\
\text { incipiente presencia } \\
\text { del narcotráfico y éste } \\
\text { tiene baja incluencia. }\end{array}$ & $\begin{array}{l}\text { Zona donde existe } \\
\text { posibilidad de } \\
\text { negociación. }\end{array}$ \\
\hline BAJO & $\begin{array}{l}\text { Zona donde se presenta } \\
\text { alta ocurrencia de los } \\
\text { delitos mencionados. }\end{array}$ & $\begin{array}{l}\text { Zona donde hay } \\
\text { presencia de todos los } \\
\text { grupos armados. }\end{array}$ & $\begin{array}{l}\text { Zona en la que existe } \\
\text { alto control por parte } \\
\text { de los grupos armados. }\end{array}$ & $\begin{array}{l}\text { Zona donde hay } \\
\text { presencia y control } \\
\text { social, político y } \\
\text { económico del } \\
\text { narcotráfico. }\end{array}$ & $\begin{array}{l}\text { Zona en la que no hay } \\
\text { posibilidad alguna de } \\
\text { negociación. }\end{array}$ \\
\hline
\end{tabular}




\subsubsection{Estructura de poder}

Para la definición sociológica de esta cualidad, se partió de la teoría weberiana sobre los tipos de dominación (Weber, 1944).

En términos del proceso de evaluación de tierras, la estructura de poder juega un papel decisivo en tanto que es ella la que permite u obstaculiza la ejecución de las medidas propuestas en dicho proceso.

Antes de entrar a analizar la Estructura Dominante en la zona, es necesario definir dos conceptos fundamentales para su comprensión, ellos son:

\section{a. Poder}

Significa la probabilidad de imponer la propia voluntad, dentro de una relación social, aun contra toda resistencia y cualquiera que sea el fundamento de esa probabilidad.

\section{b. Dominación}

Es la probabilidad de encontrar obediencia dentro de un grupo determinado para mandatos específicos.

Se pueden distinguir tres tipos de dominación según sus pretensiones típicas de "legitimidad":

- De carácter racional: que descansa en la creencia en la legalidad de ordenaciones estatuidas y de los derechos de mando de los llamados por esas ordenaciones a ejercer la autoridad (autoridad legal).

- De carácter tradicional: que descansa en la creencia cotidiana en la santidad de las tradiciones que rigieron desde lejanos tiempos y en la legitimidad de los señalados por esa tradición para ejercer la autoridad (autoridad tradicional).

- De carácter carismático: que descansa en la entrega extracotidiana a la santidad, heroísmo o ejemplaridad de una persona y a las ordenaciones por ella creadas o reveladas, es decir, el llamado de su dios (autoridad carismática).

\subsubsection{Dominación legal con admi- nistración burocrática}

Las categorías fundamentales de la dominación legal son:

Un ejercicio continuado, sujeto a la ley, de funciones cuya competencia está inscrita en un ámbito de deberes y servicios objetivamente limitados en virtud de una distribución de funciones.

- Atribución de poderes necesarios para su realización.

- Fijación estricta de los medios coercitivos.

- Jerarquía administrativa, es decir, la ordenación de las autoridades fijas con facultades de regulación e inspección.

- Las "reglas" según las cuales hay que proceder pueden ser técnicas o normas. 
- Rige el principio de la separación plena entre el cuadro administrativo y los medios de administración y producción.

- La totalidad del cuadro administrativo se compone, en el tipo más puro, de funcionarios individuales que se caracterizan por ser personas libres, que se deben sólo a los deberes objetivos de su cargo.

\subsubsection{Dominación tradicional}

Debe entenderse que una dominación es tradicional cuando su legitimidad descansa en la santidad de ordenaciones y poderes de mando heredados desde tiempos lejanos "desde tiempo inmemorial", creyéndose en ella en méritos de esa santidad. El soberano no es "un superior" sino un señor personal, su cuadro administrativo no está constituido por "funcionarios" sino por "servidores", los dominados no son "miembros" de la asociación sino "compañeros tradicionales", "súbditos". Las relaciones del cuadro administrativo para con el soberano no se determinan por el poder objetivo del cargo (característica del poder burocrático), sino por la fidelidad personal del servidor.

\subsubsection{Dominación carismática}

Debe entenderse por "carisma" la cualidad que pasa por extraordinaria (que es mágica en su origen), de una personalidad, por cuya virtud se la considera en posesión de fuerzas sobrenaturales o sobrehumanas, no asequibles a cualquier otro, o como enviados del dios, o como ejemplar $y$, en consecuencia como jefe, caudillo, guía o líder.
Sobre la validez del carisma reside el reconocimiento de su virtud por parte de los dominados; reconocimiento que se mantiene por, "corroboración" de las supuestas cualidades carismáticas. Este "reconocimiento" es, sicológicamente, una entrega puramente personal y llena de fe surgida del entusiasmo o de la indigencia y la esperanza.

El cuadro administrativo de los imperantes carismáticos no es ninguna burocracia, y menos aún una burocracia profesional.

En la tabla número 11 se observa la clasificación de los anteriores aspectos.

\subsubsection{Organización y participación social}

El criterio para incluir esta variable en la caracterización de la zona es la incidencia que tiene la organización y la participación social en el desarrollo de una región o área determinada, dada la capacidad para la reivindicación de derechos y defensa de asuntos comunitarios en torno a la búsqueda de soluciones a una problemática común.

La tabla 12 ilustra estos aspectos:

Cuando se habla de las propuestas y solicitudes de la comunidad se hace referencia a aquellas que son económicamente viables, ambientalmente sostenibles y prioritarias.

196 Sandra Martínez B. - Zaida Patiño G. - Olga Sánchez P. 
Tabla No. 11

Tabla de estructura de poder

\begin{tabular}{|c|l|l|l|}
\hline GRADO & $\begin{array}{c}\text { CARACTERISTICAS } \\
\text { DEL PODER } \\
\text { BUROCRATICO* }\end{array}$ & $\begin{array}{c}\text { CARACTERISTICAS } \\
\text { DEL PODER } \\
\text { TRADICIONAL** }\end{array}$ & $\begin{array}{c}\text { CARACTERISTICAS } \\
\text { DEL PODER } \\
\text { CARISMATICO*** }\end{array}$ \\
\hline ALTO & $\begin{array}{l}\text { Se presentan todas las } \\
\text { características puras de } \\
\text { dominación legal } \\
\text { burocrática, no viciadas } \\
\text { por intereses de grupos } \\
\text { políticos y/o económicos. }\end{array}$ & $\begin{array}{l}\text { Se Presentan todas las } \\
\text { características puras de } \\
\text { dominación tradicional. }\end{array}$ & $\begin{array}{l}\text { Se presentan todas las } \\
\text { características puras de } \\
\text { dominación carismática. }\end{array}$ \\
$\begin{array}{l}\text { Se observa cierta transición } \\
\text { desde lo catalogado como } \\
\text { bajo, hacia lo catalogado } \\
\text { como alto. }\end{array}$ & $\begin{array}{l}\text { La influencia externa se ha } \\
\text { adoptado de tal forma que } \\
\text { su impacto no es negativo } \\
\text { para el bienestar de la } \\
\text { comunidad. }\end{array}$ & $\begin{array}{l}\text { La influencia externa se ha } \\
\text { adoptado de tal forma que } \\
\text { su impacto no es negativo } \\
\text { para el bienestar de la } \\
\text { comunidad. }\end{array}$ \\
$\begin{array}{l}\text { Está estatuida legalmente } \\
\text { la administración } \\
\text { burocrática legal, pero, } \\
\text { mediada o viciada por } \\
\text { acciones arbitrarias, en } \\
\text { virtud de intereses de } \\
\text { grupos políticos y/o } \\
\text { económicos. }\end{array}$ & $\begin{array}{l}\text { Se ha alterado el orden } \\
\text { legítimamente tradicional, } \\
\text { causando impactos } \\
\text { negativos sobre las formas } \\
\text { culturales de organización. }\end{array}$ & $\begin{array}{l}\text { La dominación carismática } \\
\text { pierde legitimidad, bien sea } \\
\text { por ausencia verdadera de } \\
\text { virtudes de quien ejerce el } \\
\text { dominio, o por pérdida } \\
\text { poder de corroboración. }\end{array}$ \\
\hline
\end{tabular}

* Se presenta en Estados modernos.

** Se presenta en sociedades con características culturales tradicionales como las indígenas.

*** Es ocasional, pero se puede presentar en zonas donde existen grupos de carácter místico o metafísico.

\subsection{Tabla de oferta social}

Para esta sección del trabajo, se partió de la tabla parcial donde se encuentran todas las cualidades desagrupadas en sus correspondientes variables, las cuales estaban calificadas independientemente. Después de hacer una valoración de las variables que conformaban cada cualidad se procedió a calificarla definitivamente en la Tabla de Oferta Social Agrupada. Ver tablas No. 13 y 14.
Es necesario precisar aquí que, la calificación definitiva de cada cualidad se hace mediante el criterio de la o el evaluador.

\subsection{Determinacion de los TUT}

De acuerdo a los datos obtenidos de la evaluación física de las unidades de tierra, se escogieron dos TUT para las unidades Jaraquiel y Nariño, siendo estos Arroz y Pasto Guinea. 
Tabla No. 12

Tabla de organización y participación social

\begin{tabular}{|c|c|c|c|c|}
\hline GRADO & $\begin{array}{c}\text { ESPACIOS DE } \\
\text { PARTICIPACION }\end{array}$ & $\begin{array}{c}\text { NIVEL DE } \\
\text { ORGANIZACION }\end{array}$ & $\begin{array}{c}\text { GRADO DE } \\
\text { PARTICIPACION }\end{array}$ & $\begin{array}{c}\text { INFLUENCIA } \\
\text { DE LA COMUNIDAD } \\
\text { EN LA TOMA DE } \\
\text { DECISIONES }\end{array}$ \\
\hline ALTO & $\begin{array}{l}\text { Existen diversos } \\
\text { espacios promovidos } \\
\text { por la administración } \\
\text { tales como Consejos } \\
\text { territoriales de } \\
\text { planeación, CMDR, } \\
\text { veedurías } \\
\text { comunitarias, etc. }\end{array}$ & $\begin{array}{l}\text { La(s) organizaciones } \\
\text { existentes representan } \\
\text { los intereses de todos } \\
\text { los sectores de la } \\
\text { población. }\end{array}$ & $\begin{array}{l}\text { La comunidad está } \\
\text { comprometida con } \\
\text { el desarrollo de la } \\
\text { localidad. }\end{array}$ & $\begin{array}{l}\text { Se gestionan e } \\
\text { implementan todas las } \\
\text { solicitudes y/o } \\
\text { propuestas de la } \\
\text { comunidad u } \\
\text { organizaciones } \\
\text { existentes. }\end{array}$ \\
\hline MEDIO & $\begin{array}{l}\text { Existen solo algunos } \\
\text { de estos espacios }\end{array}$ & $\begin{array}{l}\text { Las organizaciones } \\
\text { existentes solo } \\
\text { representan algunos } \\
\text { sectores de la } \\
\text { población }\end{array}$ & $\begin{array}{l}\text { Fluctúa entre la } \\
\text { participación y la } \\
\text { no participación. }\end{array}$ & $\begin{array}{l}\text { Algunas de las } \\
\text { solicitudes y/o } \\
\text { propuestas } \\
\text { realizadas por la } \\
\text { comunidad se } \\
\text { gestionan } \\
\text { o implementan. }\end{array}$ \\
\hline BAJO & $\begin{array}{l}\text { No existen espacios } \\
\text { promovidos por la } \\
\text { administración. }\end{array}$ & $\begin{array}{l}\text { No existen que } \\
\text { representen a ninguno } \\
\text { de los sectores de la } \\
\text { población }\end{array}$ & $\begin{array}{l}\text { La comunidad es } \\
\text { escéptica, indiferente } \\
\text { o apática frente a las } \\
\text { necesidades de la } \\
\text { localidad. }\end{array}$ & $\begin{array}{l}\text { Indiferencia frente a las } \\
\text { propuestas de la } \\
\text { comunidad. }\end{array}$ \\
\hline
\end{tabular}

Cuando se habla de las propuestas y solicitudes de la comunidad se hace referencia a aquellas que son económicamente viables, ambientalmente sostenibles y prioritarias.

198 Sandra Martínez B. - Zaida Patiño G. - Olga Sánchez P. 
Tabla No. 13

Tabla de oferta social desagrupada

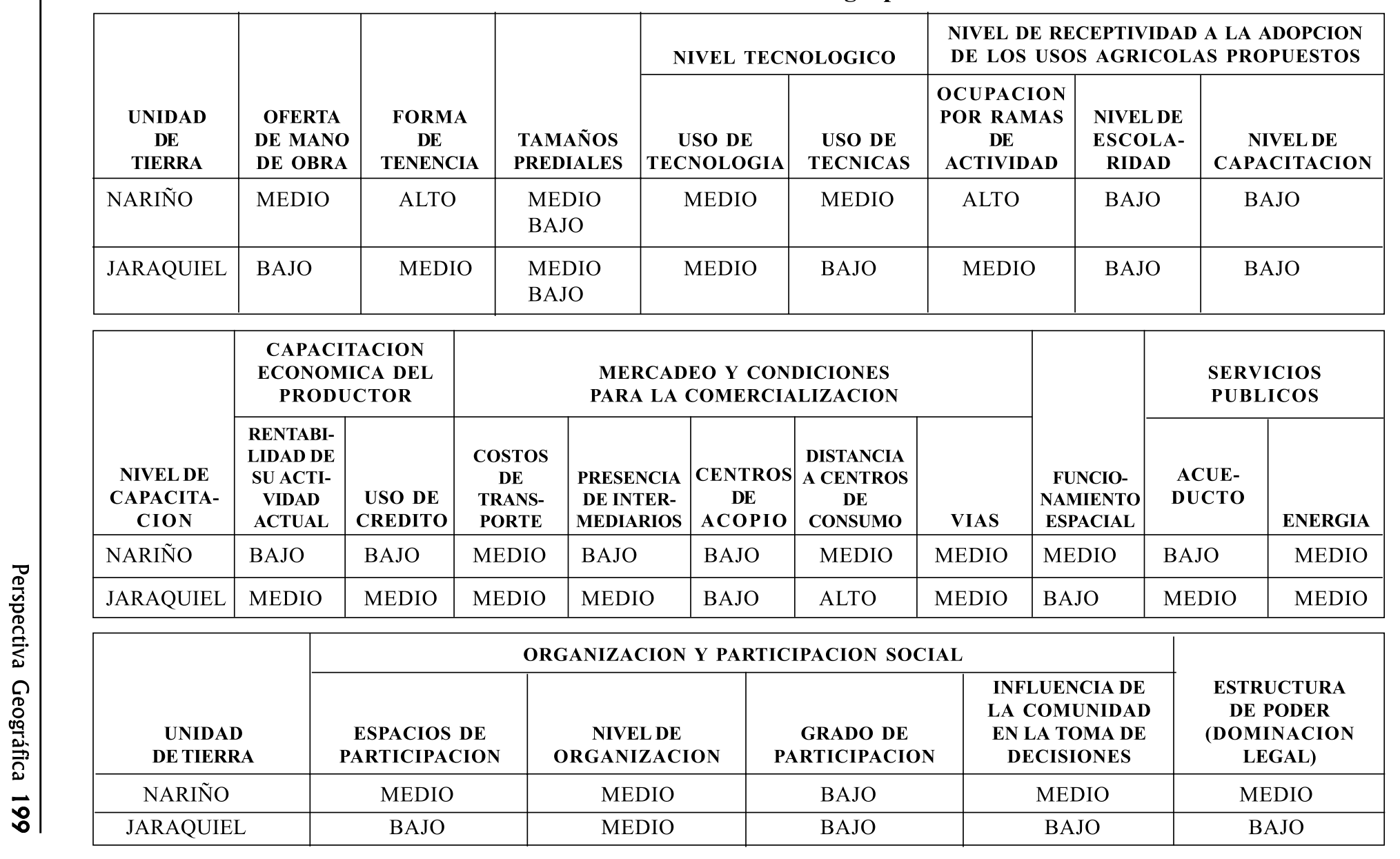


Tabla No. 14

Tabla de oferta social agrupada

\begin{tabular}{|c|c|c|c|c|c|c|c|c|c|c|c|c|}
\hline APTITUD & $\begin{array}{c}\text { MANO } \\
\text { DE } \\
\text { OBRA }\end{array}$ & $\begin{array}{c}\text { FORMA } \\
\text { DE } \\
\text { TENENCIA } \\
\end{array}$ & \begin{tabular}{|l} 
TAMAÑO \\
PREDIAL
\end{tabular} & \begin{tabular}{|c|} 
NIVEL \\
TECNO- \\
LOGICO \\
\end{tabular} & $\begin{array}{l}\text { NIVEL DE } \\
\text { RECEP- } \\
\text { TIVIDAD }\end{array}$ & \begin{tabular}{|} 
CAPAC. \\
DE \\
INVER- \\
SION \\
\end{tabular} & $\begin{array}{c}\text { MERCADEO } \\
\text { Y COMER- } \\
\text { CIALIZAC. } \\
\end{array}$ & \begin{tabular}{|c} 
FUNCIO- \\
NAMIENTO \\
ESPACIAL \\
\end{tabular} & \begin{tabular}{|c} 
SERVI- \\
CIOS \\
PUBLICOS
\end{tabular} & $\begin{array}{c}\text { ORDEN } \\
\text { PUBLICO }\end{array}$ & $\begin{array}{l}\text { ESTRUC- } \\
\text { TURA DE } \\
\text { PODER } \\
\end{array}$ & \begin{tabular}{|c} 
ORGANI- \\
ZACION \\
Y \\
PARTICI- \\
PACION \\
\end{tabular} \\
\hline NARIÑO & MEDIO & ALTO & MEDIO & MEDIO & MEDIO & BAJO & BAJO & MEDIO & BAJO & MEDIO & MEDIO & MEDIO \\
\hline $\begin{array}{l}\text { JARA- } \\
\text { QUIEL }\end{array}$ & BAJO & MEDIO & MEDIO & BAJO & BAJO & MEDIO & MEDIO & BAJO & MEDIO & BAJO & BAJO & BAJO \\
\hline
\end{tabular}

Tabla No. 15

Tabla de requerimientos sociales para el cultivo de arroz

\begin{tabular}{|c|c|c|c|c|c|c|c|c|c|c|c|c|}
\hline APTITUD & $\begin{array}{c}\text { MANO } \\
\text { DE } \\
\text { OBRA }\end{array}$ & \begin{tabular}{|c|} 
FORMA \\
DE \\
TENENCIA \\
\end{tabular} & $\begin{array}{l}\text { TAMAÑO } \\
\text { PREDIAL }\end{array}$ & $\begin{array}{c}\text { NIVEL } \\
\text { TECNO- } \\
\text { LOGICO }\end{array}$ & $\begin{array}{l}\text { NIVEL DE } \\
\text { RECEP- } \\
\text { TIVIDAD }\end{array}$ & $\begin{array}{c}\text { CAPAC. } \\
\text { DE } \\
\text { INVER- } \\
\text { SION } \\
\end{array}$ & $\begin{array}{c}\text { MERCADEO } \\
\text { Y COMER- } \\
\text { CIALIZAC. } \\
\end{array}$ & \begin{tabular}{|} 
FUNCIO- \\
NAMIENTO \\
ESPACIAL \\
\end{tabular} & $\begin{array}{c}\text { SERVI- } \\
\text { CIOS } \\
\text { PUBLICOS }\end{array}$ & $\begin{array}{c}\text { ORDEN } \\
\text { PUBLICO }\end{array}$ & $\begin{array}{c}\text { ESTRUC- } \\
\text { TURA DE } \\
\text { PODER } \\
\end{array}$ & $\begin{array}{c}\text { ORGANI- } \\
\text { ZACION } \\
\text { Y } \\
\text { PARTICI- } \\
\text { PACION } \\
\end{array}$ \\
\hline A1 & ALTO & $\begin{array}{l}\text { ALTO/ } \\
\text { MEDIO }\end{array}$ & $\begin{array}{c}\text { BAJO/ } \\
\text { ALTO/ } \\
\text { MEDIO }\end{array}$ & ALTO & ALTO & MEDIO & MEDIO & MEDIO & MEDIO & ALTO & $\begin{array}{c}\text { ALTO/ } \\
\text { MEDIO }\end{array}$ & ALTO \\
\hline A3 & MEDIO & BAJO & $\begin{array}{l}\text { MUY } \\
\text { BAJO }\end{array}$ & BAJO & BAJO & BAJO & BAJO & BAJO & BAJO & MEDIO & MEDIO & BAJO \\
\hline $\mathrm{N}$ & BAJO & BAJO & $\begin{array}{l}\text { MUY } \\
\text { BAJO }\end{array}$ & BAJO & BAJO & BAJO & BAJO & BAJO & BAJO & BAJO & BAJO & BAJO \\
\hline
\end{tabular}


Tabla No. 16

Tabla de requerimientos sociales para el cultivo de pasto Guinea

\begin{tabular}{|c|c|c|c|c|c|c|c|c|c|c|c|c|}
\hline APTITUD & $\begin{array}{c}\text { MANO } \\
\text { DE } \\
\text { OBRA }\end{array}$ & \begin{tabular}{|c|} 
FORMA \\
DE \\
TENENCIA
\end{tabular} & $\begin{array}{l}\text { TAMAÑO } \\
\text { PREDIAL }\end{array}$ & $\begin{array}{c}\text { NIVEL } \\
\text { TECNO- } \\
\text { LOGICO }\end{array}$ & $\begin{array}{c}\text { NIVEL DE } \\
\text { RECEP- } \\
\text { TIVIDAD }\end{array}$ & $\begin{array}{l}\text { CAPAC. } \\
\text { DE } \\
\text { INVER- } \\
\text { SION }\end{array}$ & \begin{tabular}{|} 
MERCADEO \\
Y COMER- \\
CIALIZAC.
\end{tabular} & \begin{tabular}{|c|} 
FUNCIO- \\
NAMIENTO \\
ESPACIAL \\
\end{tabular} & $\begin{array}{c}\text { SERVI- } \\
\text { CIOS } \\
\text { PUBLICOS }\end{array}$ & $\begin{array}{c}\text { ORDEN } \\
\text { PUBLICO }\end{array}$ & $\begin{array}{c}\text { ESTRUC- } \\
\text { TURA DE } \\
\text { PODER }\end{array}$ & $\begin{array}{c}\text { ORGANI- } \\
\text { ZACION } \\
\text { Y } \\
\text { PARTICI- } \\
\text { PACION }\end{array}$ \\
\hline A1 & ALTO & MEDIO & MEDIO & ALTO & MEDIO & ALTO & MEDIO & MEDIO & ALTO & ALTO & $\begin{array}{c}\text { ALTO/ } \\
\text { MEDIO }\end{array}$ & ALTO \\
\hline A2 & MEDIO & MEDIO & MEDIO & MEDIO & MEDIO & MEDIO & MEDIO & MEDIO & MEDIO & ALTO & MEDIO & MEDIO \\
\hline A3 & BAJO & BAJO & BAJO & BAJO & BAJO & BAJO & BAJO & BAJO & BAJO & MEDIO & MEDIO & BAJO \\
\hline $\mathrm{N}$ & BAJO & BAJO & BAJO & BAJO & BAJO & BAJO & BAJO & BAJO & BAJO & BAJO & BAJO & BAJO \\
\hline
\end{tabular}


Tabla No. 17

Tabla de aptitud social para cada TUT

\begin{tabular}{|c|c|c|c|c|c|c|c|c|c|c|c|c|}
\hline APTITUD & $\begin{array}{c}\text { MANO } \\
\text { DE } \\
\text { OBRA } \\
\end{array}$ & \begin{tabular}{|c|} 
FORMA \\
DE \\
TENENCIA \\
\end{tabular} & \begin{tabular}{|l} 
TAMAÑO \\
PREDIAL \\
\end{tabular} & \begin{tabular}{|c} 
NIVEL \\
TECNO- \\
LOGICO
\end{tabular} & $\begin{array}{c}\text { NIVEL DE } \\
\text { RECEP- } \\
\text { TIVIDAD }\end{array}$ & $\begin{array}{c}\text { CAPAC. } \\
\text { DE } \\
\text { INVER- } \\
\text { SION }\end{array}$ & \begin{tabular}{|} 
MERCADEO \\
Y COMER- \\
CIALIZAC.
\end{tabular} & \begin{tabular}{|c|} 
FUNCIO- \\
NAMIENTO \\
ESPACIAL \\
\end{tabular} & \begin{tabular}{|c} 
SERVI- \\
CIOS \\
PUBLICOS
\end{tabular} & $\begin{array}{l}\text { ORDEN } \\
\text { PUBLICO }\end{array}$ & $\begin{array}{l}\text { ESTRUC- } \\
\text { TURA DE } \\
\text { PODER }\end{array}$ & \begin{tabular}{|l|} 
ORGANI- \\
ZACION \\
Y \\
PARTICI- \\
PACION
\end{tabular} \\
\hline $\begin{array}{l}\text { NARIÑO } \\
\text { ARROZ }\end{array}$ & A3 & A1 & A1 & A2 & A2 & A3 & $\begin{array}{c}\mathrm{A} 3 \\
\mathrm{~N}\end{array}$ & $\begin{array}{l}\mathrm{A} 1 / \\
\mathrm{A} 2\end{array}$ & $\begin{array}{c}\text { A3 } \\
\text { N }\end{array}$ & A3 & $\mathrm{N}$ & A2 \\
\hline $\begin{array}{l}\text { NARIÑO } \\
\text { PASTOS }\end{array}$ & A2 & $\mathrm{A} 1$ & $\begin{array}{l}\mathrm{A} 1 / \\
\mathrm{A} 2\end{array}$ & A2 & $\begin{array}{l}\mathrm{A} 1 / \\
\mathrm{A} 2\end{array}$ & $\begin{array}{c}\mathrm{A} 3 \\
\mathrm{~N}\end{array}$ & $\begin{array}{c}\mathrm{A} 3 \\
\mathrm{~N}\end{array}$ & $\mathrm{~A} 1$ & $\begin{array}{c}\text { A3 } \\
\mathrm{N}\end{array}$ & A3 & $\mathrm{N}$ & A2 \\
\hline $\begin{array}{l}\text { JARA- } \\
\text { QUIEL } \\
\text { ARROZ }\end{array}$ & $\mathrm{N}$ & $\begin{array}{l}\mathrm{A} 1 / \\
\mathrm{A} 2\end{array}$ & $\begin{array}{l}\mathrm{A} 1 / \\
\mathrm{A} 2\end{array}$ & A3 & $\begin{array}{c}\mathrm{A} 3 / \\
\mathrm{N}\end{array}$ & $\begin{array}{l}\mathrm{A} 1 / \\
\mathrm{A} 2\end{array}$ & $\begin{array}{l}\mathrm{A} 1 / \\
\mathrm{A} 2\end{array}$ & $\begin{array}{l}\text { A3 } \\
\mathrm{N}\end{array}$ & $\begin{array}{l}\mathrm{A} 1 / \\
\mathrm{A} 2\end{array}$ & $\mathrm{~N}$ & A2 & $\begin{array}{l}\text { A3 } \\
\mathrm{N}\end{array}$ \\
\hline $\begin{array}{l}\text { JARA- } \\
\text { QUIEL } \\
\text { PASTOS }\end{array}$ & $\mathrm{N}$ & $\begin{array}{l}\mathrm{A} 1 / \\
\mathrm{A} 2\end{array}$ & $\begin{array}{l}\text { A1/ } \\
\text { A2 }\end{array}$ & A3 & $\begin{array}{c}\mathrm{A} 3 / \\
\mathrm{N}\end{array}$ & A2 & $\begin{array}{l}\text { A1/ } \\
\text { A2 }\end{array}$ & $\begin{array}{c}\text { A3 } \\
\text { N }\end{array}$ & A2 & $\mathrm{N}$ & A2 & $\begin{array}{c}\text { A3 } \\
\text { N }\end{array}$ \\
\hline
\end{tabular}


Tabla No. 18

Tabla de aptitud actual

\begin{tabular}{|c|c|c|}
\hline \multicolumn{1}{|c|}{ UT } & \multicolumn{1}{|c|}{ ARROZ } & PASTO GUINEA \\
\hline NARIÑO & N MC-SP-EP & N CP-MC-SP-EP \\
JARAQUIEL & N MO-NT-NR-FE-OP-OPt & N MO-NT-FE-OP-OPt \\
\hline
\end{tabular}

MC: Mercadeo y Comercialización

SP: $\quad$ Servicios Públicos

EP: Estructura de Poder

CP: Capacidad de Inversión

MO: Mano de Obra
NR: Nivel de Receptividad

FE: Funcionamiento Espacial

OP: Orden Público

OPt: Organización y Participación

NT: Nivel Tecnológico

Tabla No. 19

Tabla de aptitud potencial

\begin{tabular}{|c|c|c|}
\hline UT & ARROZ & PASTO GUINEA \\
\hline NARIÑO & A2 & A2 \\
JARAQUIEL & A3 OP & A3 OP \\
\hline
\end{tabular}

Así entonces, conociendo las condiciones físicas necesarias para implementar estos cultivos, se procedió a elaborar la tabla de requerimientos sociales para su implementación. Ver tablas Nos. 15 y 16.

\subsection{Confrontación entre oferta y demanda social}

Aquí se enfrentan los resultados de la Oferta social de cada UT y los Requerimientos para el cultivo de Arroz y de Pasto Guinea. Esto busca determinar la aptitud de cada UT con respecto a los usos propuestos, tales resultados se observan en la tabla No. 17.

\subsection{Tabla de aptitud social actual por UT y tabla de aptitud potencial por UT}

La tabla de Aptitud Social Actual se elaboró, al igual que todas las demás, atendiendo a las condiciones de la zona de estudio (datos hipotéticos). Como puede observarse en los resultados de la tabla anterior (Tabla Parcial de Aptitud por TUT No.17), existen algunas condiciones de No Apto combinadas con otra calificación (por ejemplo la cualidad Servicios Públicos calificada con $\mathrm{A} 3$ y N), lo que, por la ley del mínimo o más bajo, debe calificarse definitivamente como No 
apto en la Tabla de Aptitud Actual. Sin embargo, la condición de $\mathrm{N}$, no debe ser motivo para revocar la implementación de determinado TUT, más bien, muestra los aspectos a los que hay que colocar especial atención para la obtención de mejores resultados. Ver tabla No. 18.

De acuerdo a lo anterior, se realizó posteriormente la tabla de Aptitud Potencial que es el resultado de la respectiva atención a los aspectos negativos que enfatizaba la Tabla de Aptitud Actual. Aspectos que, susceptibles de ser corregidos, permiten el mayor y mejor desarrollo de los TUTs propuestos y en general de las condiciones sociales de la zona. Ver Tabla No. 19.

\section{Conclusiones}

La propuesta de metodología para la evaluación social en el esquema de evaluación de tierras aquí presentada, se establece como un primer acercamiento susceptible de ser aplicada y modificada de acuerdo a las experiencias o resultados obtenidos.

La elaboración de la metodología se realizó con datos hipotéticos, teniendo en cuenta las condiciones sociales generales del departamento de Córdoba. Por tanto su aplicabilidad en otras zonas de mayor heterogeneidad o donde existan grupos sociales más específicos como indígenas, comunidades negras o comunidades campesinas de tipo tradicional, requiere de la modificación de algunos aspectos tenidos en cuenta aquí. Sin embargo se trató de generalizar al máximo posible para aquellas áreas donde a pesar de diferencias internas, no hay presencia por lo menos de comunidades indígenas y negras.

Las condiciones sociales presentan, más que un resultado definitivo para descalificar o calificar una Unidad de Tierra, la advertencia de los aspectos críticos que se deben tener en cuenta para hacer más eficaz y fructífera la implementación de diferentes TUT.

La tipología weberiana presentada para la caracterización de la estructura de poder, es útil para caracterizar otro tipo de sociedades y culturas además de la dominante en el país. A pesar de la incorporación de los diferentes tipos en la tabla de características, solo se trabaja en la tabla de oferta y requerimientos con el Tipo de dominación legal con administración burocrática. Los otros tipos, aportan para el diseño de metodológicas más especificas.

204 Sandra Martínez B. - Zaida Patiño G. - Olga Sánchez P. 


\section{Bibliografía}

IGAC. “Atlas Regional del Caribe”. Bogotá 1978.

DANE. Censo de Población, 1993.

FAO. "Directivas: evaluación de Tierras para la Agricultura en Secano". Boletín de Suelos de la FAO No. 52. Roma, 1985.

IGAC. "Guía Metodológica para la Formulación del Plan de Ordenamiento Territorial Municipal”. Bogotá, 1997.

IGAC. "Estructura Urbano Regional Colombiana”. Bogotá. 1986.

IGAC. "Monografía del departamento de Córdoba”. Bogotá. 1992.

Weber, Max. "Economía y Sociedad”. Fondo de Cultura Económica. Bogotá, 1944. 
206 Sandra Martínez B. - Zaida Patiño G. - Olga Sánchez P. 